\title{
Lithocarpus dahuoaiensis (Fagaceae), a new species from Lam Dong Province, Vietnam
}

\author{
Nguyen Van Ngoc ${ }^{1,2}$, Luong Van Dung ${ }^{2}$, Shuichiro Tagane', Hoang Thi Binh ${ }^{1,2}$, \\ Hoang Thanh Son ${ }^{3}$, Vo Quang Trung ${ }^{4}$, Tetsukazu Yahara' \\ I Center for Asian Conservation Ecology, Kyushu University, 744 Motooka, Fukuoka, 819-0395, Japan 2 \\ Department of Biology, Dalat University, 01 - Phu Dong Thien Vuong, Dalat, Vietnam 3 Silviculture Research \\ Institute, Vietnamese Academy of Forest Sciences, Ha Noi, 10999, Vietnam 4 Dong Nai Culture and Nature \\ Reserve, Ma Da, Vinh Cuu, Dong Nai, Vietnam \\ Corresponding author: Nguyen Van Ngoc (ngocnv@dlu.edu.vn)
}

Academic editor: Hanno Schaefer | Received 10 July 2016 | Accepted 5 August 2016 | Published 18 August 2016

Citation: Ngoc NV, Dung LV, Tagane S, Binh HT, Son HT, Trung VQ, Yahara T (2016) Lithocarpus dahuoaiensis (Fagaceae), a new species from Lam Dong Province, Vietnam. PhytoKeys 69: 23-30. doi: 10.3897/phytokeys.69.9821

\begin{abstract}
Lithocarpus dahuoaiensis Ngoc \& L. V. Dung, a new species from the Central highland of Vietnam, is described and illustrated. The new species is morphologically similar to Lithocarpus macphailii (M. R. Hend.) Barnett or Lithocarpus encleisocarpus (Korth.) A. Camus in having completely entire leaf margin, solitary cupule, long stalks of fruits, deeply cup-shaped or turbinate cupules, with a number of horizontal filiform lines. The species differs in its nut enclosure ca. $1 / 2-2 / 3$ of the nut, adaxially glabrous leaf blades, secondary veins 11-12 pairs and faintly to very faintly visible hairs on the outside of the cupule. A table showing the morphological comparison of Lithocarpus dahuoaiensis with Lithocarpus macphailii and Lithocarpus encleisocarpus is also provided.
\end{abstract}

\section{Keywords}

Da Huoai, Fagaceae, Lam Dong Province, Lithocarpus, Lithocarpus dahuoaiensis, Vietnam 


\section{Introduction}

Lithocarpus Blume is the second largest genus of the family Fagaceae, comprising 341 species (The Plant List 2013). The genus is commonly known as Stone Oaks and widely distributed throughout the tropical and sub-tropical broad-leaved evergreen forests in East and Southeast Asia, extending to New Guinea (Cannon 2001, Phengklai 2008). In North America, one species of Lithocarpus, L. densiflorus (Hook. \& Arn.) had been known, but has recently been treated as a member of a new monotypic genus Notholithocarpus (Manos et al. 2008). The center of diversity is in East to Southeast Asia, where 123 species are enumerated in China (Huang et al. 1999), 58 species in Thailand (Phengklai 2008, Strijk et al. 2014) and 115 species in Vietnam (Ho 2003, Ban 2005).

In Vietnam, the species of Fagaceae are highly diversified and can be seen in various forest types, from dry evergreen forest at lowland to montane evergreen forest at high mountains. A total of 216 species and two varieties in six genera have been recorded in the country (Ho 1999, Ban 2005, Linh et al. 2013, Vuong and Xia 2014), which represents 66\% of the total world genera and $24 \%$ of the total world species diversity in this family. One species of Fagus L., two species of Castanea Mill., 54 species of Castanopsis (D. Don) Spach., 43 species of Quercus L., one species of Trigonobalanus Forman and 115 species with two varieties of Lithocarpus have been found, indicating that Lithocarpus is the largest and most diversified genus of the family in Vietnam. Recently, several taxonomic works on Fagaceae of Vietnam were published (Deng et al. 2010, Linh et al. 2013, Vuong and Xia 2014), indicating that taxonomic studies of the family Fagaceae in Vietnam are still required.

Lam Dong Province is located in Central highland of Vietnam (Fig. 1) and has long been known as one of the biodiversity hotspots in Vietnam. In June 2015, the International coordinating Council of UNESCO's Man and the Biosphere Program added 20 new sites to the World Network of Biosphere Reserves, among which Langbiang biosphere reserve in Lam Dong Province was one of the sites selected (UNESCO 2015). In the region, 3,490 species of vascular plants have been recorded, including 131 and 45 threatened species which are listed in Vietnam's Red Book and IUCN Red List Categories, respectively (Ban et al. 2007, IUCN 2012). As for Fagaceae, 90 species, including 30 species of Lithocarpus, are recorded from Lam Dong Province (Ho 2003, Ban 2005, Dung 2005).

During our floristic inventory in Lam Dong Province in 2015, we discovered several individuals resembling species of the genus Lithocarpus. Further study revealed that these did not resemble any species described previously. Here, these are described and illustrated as Lithocarpus dahuoaiensis Ngoc \& L. V. Dung, sp. nov.

\section{Material and methods}

The new species was discovered through literature review, as well as a thorough examination of specimens in the herbaria at ANDA, BKF, DLU, FU, HN, K, KYO, L, P, VNM and digital images of specimens on JSTOR Global Plants (https://plants.jstor. org/), Herbier National de Paris, Muséum National d'Histoire Naturelle (P). 


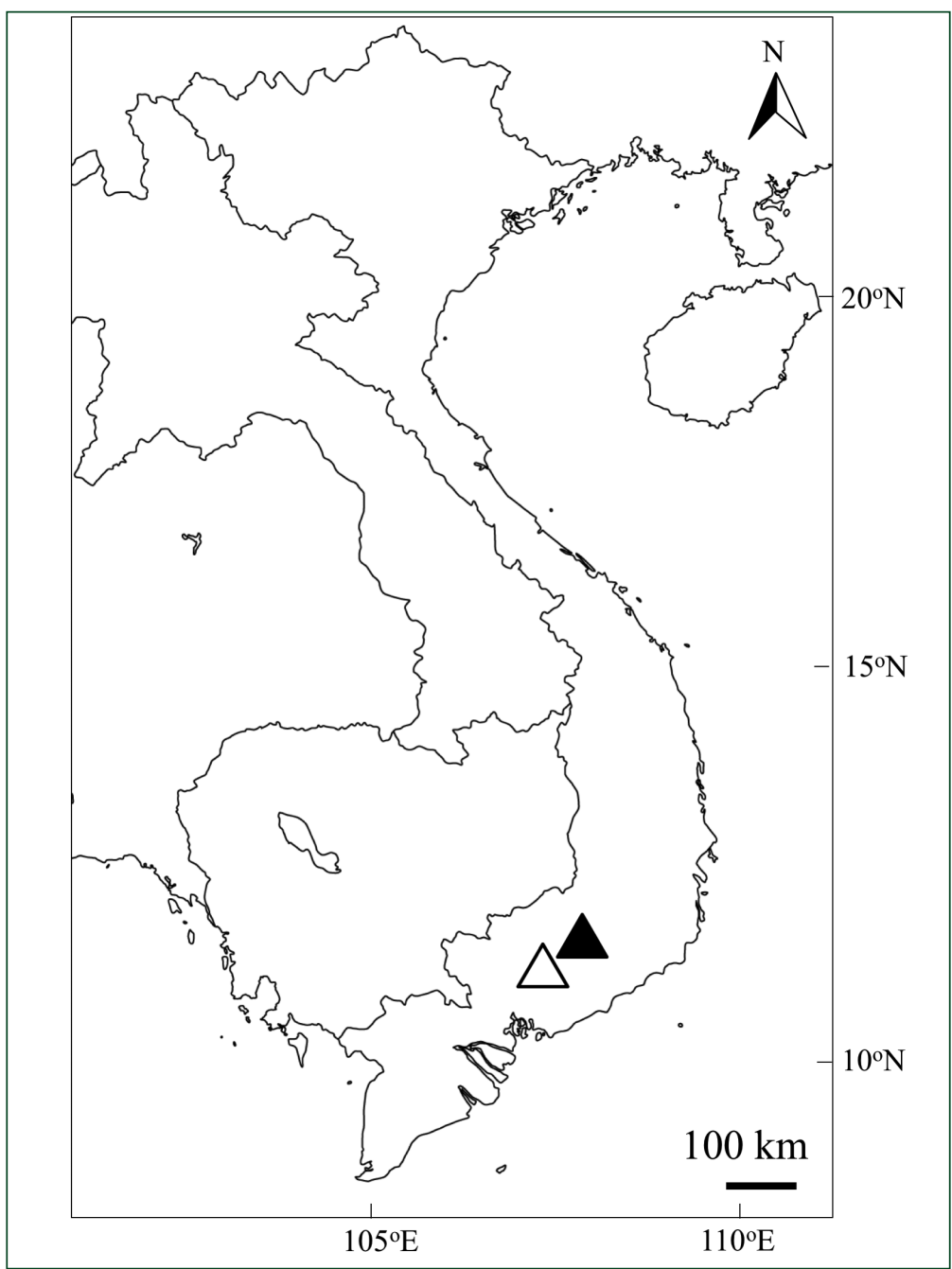

Figure I. Distribution map of Lithocarpus dahuoaiensis Ngoc \& L. V. Dung. Black triangle, Da Huoai, Lam Dong Province (Type locality); White triangle, Dong Nai Culture and Nature Reserve, Dong Nai Province.

\section{Taxonomy}

\section{Lithocarpus dahuoaiensis Ngoc \& L. V. Dung, sp. nov.} urn:Isid:ipni.org:names:60472844-2

Figs 2, 3

Diagnosis. Lithocarpus dahuoaiensis is morphologically similar to Lithocarpus macphailii (M.R.Hend.) Barnett and Lithocarpus encleisocarpus (Korth.) A. Camus in having a completely entire leaf margin, solitary cupule, long stalks of fruits, deeply cup-shaped or turbinate cupules with the number of horizontal filiform lines. But $L$. dahuoaiensis is 
distinct by its cupules enclosing ca. 1/2-2/3 of the nuts (vs. cupules almost completely covering the nut in L. macphailii and L. encleisocarpus), surface of the cupule densely tomentose inside and subtle hairy to very subtle hairy outside (vs. outside densely fulvous tomentose in L. macphailii and outside densely fulvous tomentose by stellate hairs in L. encleisocarpus), leaf blades glabrous adaxially, undersides covered with very short soft hairs and subtle (vs. densely glaucous tomentose with adpressed, stellate hairs abaxially in L. macphailii, pubescent then glabrescent abaxially in L. encleisocarpus), secondary veins $11-12$ pairs (vs. $12-16$ pairs in $L$. macphailii and 8-10 pairs in L. encleisocarpus).

Type. VIETNAM. Lam Dong Province, Da Huoai, along the 20 National Highway, in the lowland evergreen forest, alt. $225 \mathrm{~m}, 11^{\circ} 23^{\prime} 32.5^{\prime \prime} \mathrm{N}, 107^{\circ} 33^{\prime} 56.3^{\prime \prime E}, 14$ June 2015, N. Nguyen, D. Luong, B. Hoang, T. Nguyen V3194 (holotype: KYO!; isotypes: DLU!, FU!, HN!, K!, P!, VNM!).

Description. Evergreen tree, up to $35 \mathrm{~m}$ tall; young branchlets pubescent with white hairs, soon glabrous, greyish green in vivo and blackish brown in sicco; terminal buds ca. 10-12 mm long, bud scale 4-6 mm long, densely covered with whitish hairs. Stipules not seen. Leaves alternate, blades broadly elliptic to slightly obovate, ca. $15-27 \times 6-11 \mathrm{~cm}$, thickly coriaceous, base cuneate, margin entire, slightly recurved, apex acuminate or caudate, acumen ca. 5-10 mm long, glabrous adaxially, subtle short soft hairs abaxially; midrib slightly raised above, distinctly raised below glabrous, greenish yellow in vivo, reddish brown in sicco; secondary veins 11-12 pairs, clearly visible on both sides, flat to slightly prominent adaxially, prominent abaxially, veins curving smoothly and disappearing near margins, at an angle of 55-65 degree from the midrib, tertiary veins scalariform, invisible to faintly visible on both surfaces; petioles ca. 10-15 mm long, rounded, thickened, pubescent when young, glabrescent later. Flowers not seen. Infructescences erect, woody, $25 \mathrm{~cm}$ long, rachis densely adpressed hairy. Acorn solitary, ovoid or turbinate, $13-15 \mathrm{~mm}$ in height, $20-23 \mathrm{~mm}$ in diam. (including cupule); fruiting stalk 3-5 $\mathrm{mm}$ long, densely fulvous tomentose hair. Cupules, turbinate, base a little broader than the upper part, densely tomentose inside and invisible or subtle hairy outside, lamellate, wall woody, sometimes crackled, enclosing ca. $1 / 2-2 / 3$ of the nut, $12-14 \mathrm{~mm}$ in height, $19-22 \mathrm{~mm}$ in diam., bractlets triangular, obscure, forming 6-7 dimly concentric flanges. Mature nut $19-22 \mathrm{~mm}$ in height, $20-23 \mathrm{~mm}$ in diam., densely white tomentose; scar created by cupule at the base is deeply concave, ca. $13-15 \mathrm{~mm}$ in diam.; wall woody, crackled; apex abruptly acuminate, ca. $1.5-2 \mathrm{~mm}$ in height.

Phenology. Mature fruits were collected in June.

Distribution and habitat. Vietnam (so far known from Lam Dong Province and Dong Nai Province split by a boundary along National highway 20). (Figure 1)

Etymology. The specific epithet is derived from the type locality, Da Huoai, Lam Dong Province, Central Highland Vietnam.

Conservation status. Data Deficient (DD). Three fruiting individuals were found at the type locality, along the Chuoi pass of the 20 National highway. In addition, a 


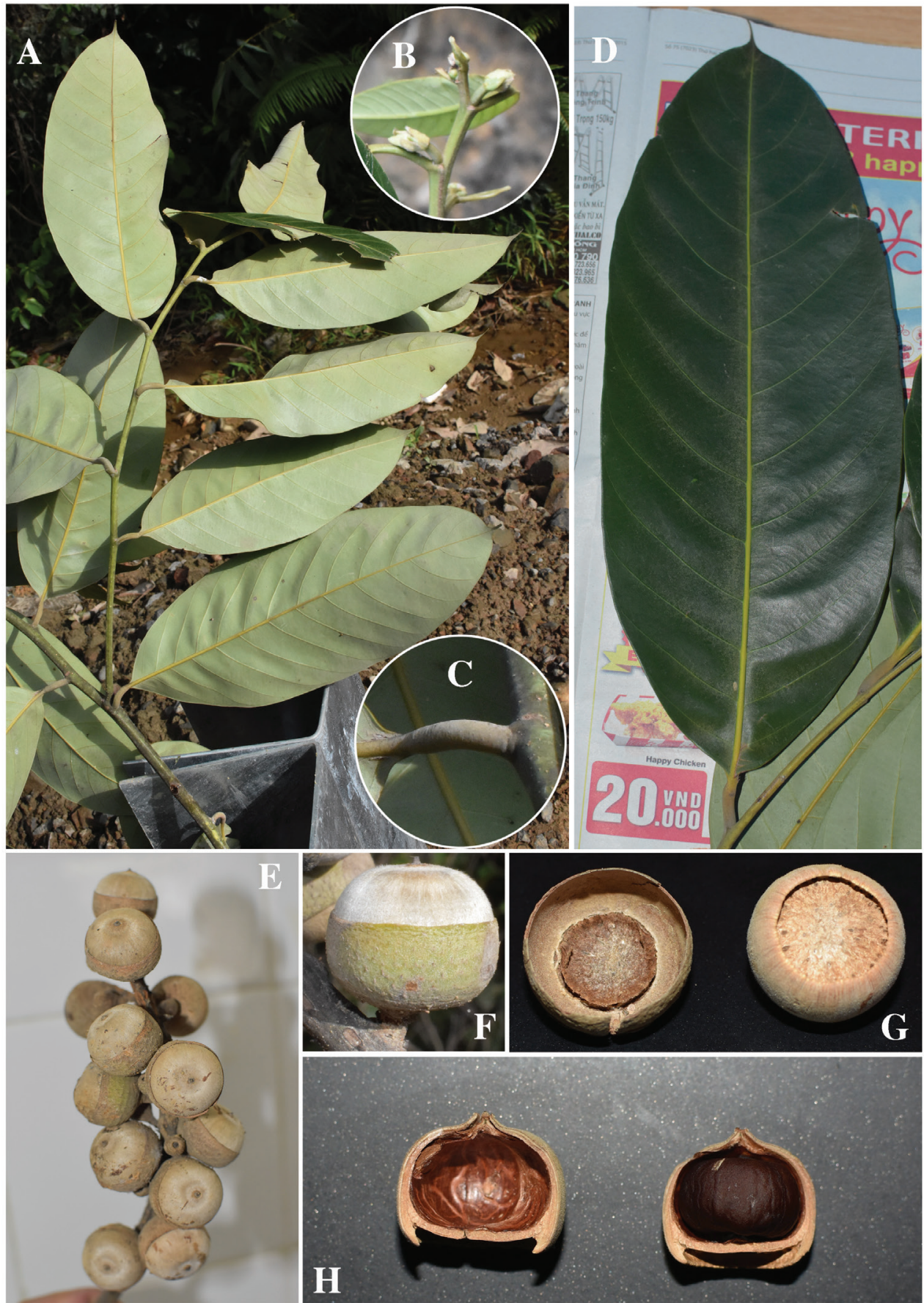

Figure 2. Lithocarpus dahuoaiensis Ngoc \& L. V. Dung. A Leafy twig B Buds C Petiole D Abaxial surface of mature Leaf $\mathbf{E}$ Infructescence $\mathbf{F}$ Mature fruit $\mathbf{G}$ Cupule (left) and bottom of nut (right) $\mathbf{H}$ Vertical sections of nut. 

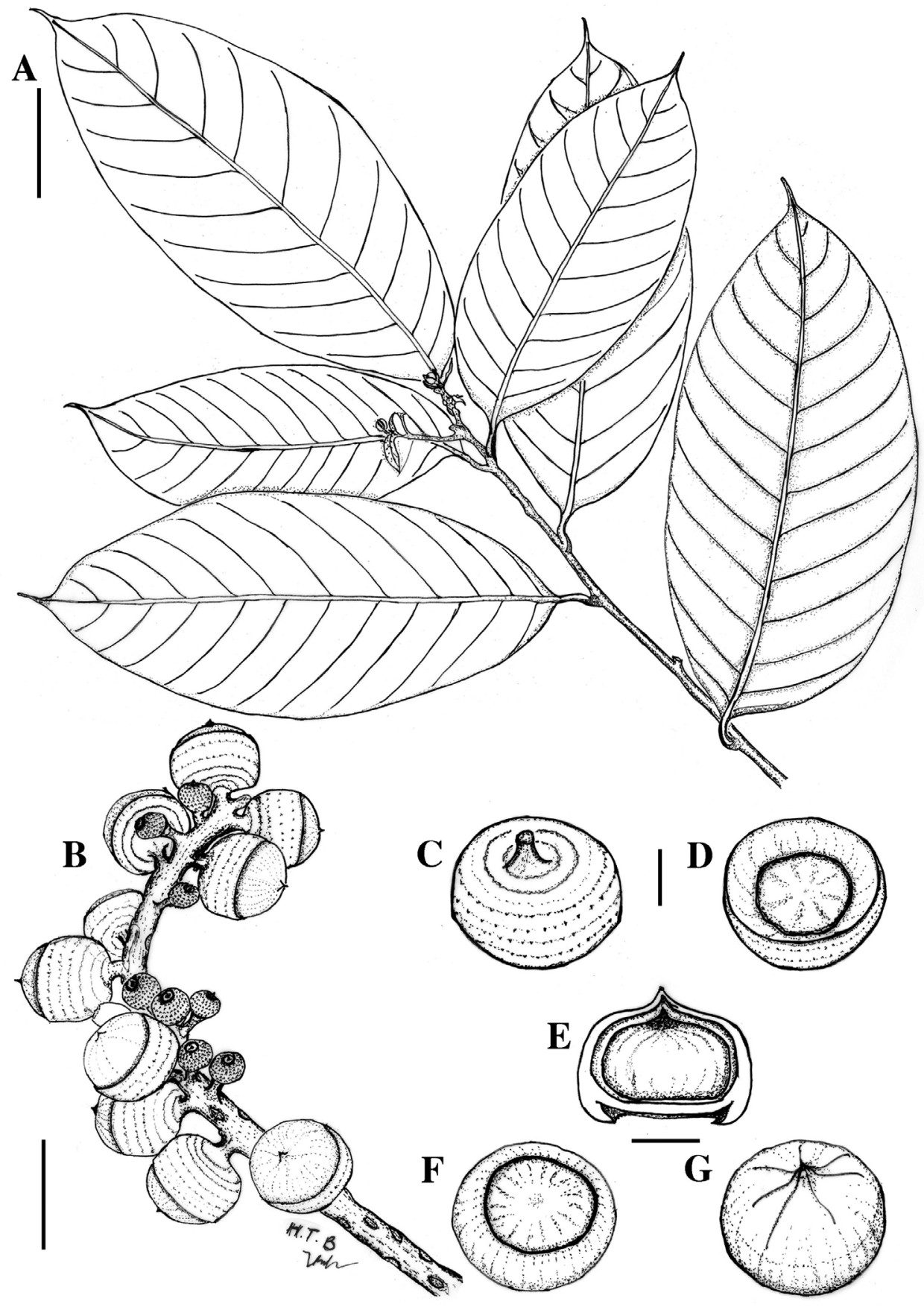

Figure 3. Line drawing of Lithocarpus dahuoaiensis Ngoc \& L. V. Dung. A Leafy twig B Infructescence C, D Cupule E Vertical section of mature nut $\mathbf{F}, \mathbf{G}$ Mature nut. Scale bars $\mathbf{A}, \mathbf{B}=5 \mathrm{~cm} ; \mathbf{C}-\mathbf{G}=10 \mathrm{~mm}$. 
Table I. Morphological comparison between Lithocarpus dahuoaiensis Ngoc \& L. V. Dung, sp. nov. with Lithocarpus macphailii (M.R.Hend.) Barnett and Lithocarpus encleisocarpus (Korth.) A.Camus. (The measurements of L. macphailii and L. encleisocarpus derive from Soepadmo 1972)

\begin{tabular}{|c|c|c|c|}
\hline Characters & L. dabuoaiensis & L. macphailii & L. encleisocarpus \\
\hline Leaf margin & Entire & Entire & Entire \\
\hline Leaf surface & $\begin{array}{l}\text { Glabrous above, very } \\
\text { short soft hairs and sub- } \\
\text { tle beneath }\end{array}$ & $\begin{array}{l}\text { Densely glaucous tomen- } \\
\text { tose with adpressed, stel- } \\
\text { late hair on lower surface }\end{array}$ & $\begin{array}{l}\text { Subglabrous on upper } \\
\text { surface, densely glaucous } \\
\text { adpressed stellate-hairy } \\
\text { on lower surfaces }\end{array}$ \\
\hline Leaf size $(\mathrm{cm})$ & $15-27 \times 6-11$ & $15-22 \times 6-8$ & $12-15 \times 4-6$ \\
\hline Length of petioles & $10-15 \mathrm{~mm}$ long & $10-17 \mathrm{~mm}$ long & 5-15 $\mathrm{mm}$ long \\
\hline $\begin{array}{l}\text { Number of second- } \\
\text { ary veins }\end{array}$ & 11-12 pairs & $12-16$ pairs & $(7-) 8-10(-12)$ pairs \\
\hline Length of fruit stalk & $3-5 \mathrm{~mm}$ long & Up to $5 \mathrm{~mm}$ long & $10-15 \mathrm{~mm}$ long \\
\hline Acorn size (in diam.) & $20-23 \mathrm{~mm}$ & $20-25 \mathrm{~mm}$ & $20-27 \mathrm{~mm}$ \\
\hline Cupule size & $\begin{array}{c}12-14 \mathrm{~mm} \text { high } \times 20-23 \\
\mathrm{~mm} \text { across }\end{array}$ & $\begin{array}{c}7-15 \mathrm{~mm} \text { high } \times 20-30 \\
\mathrm{~mm} \text { across }\end{array}$ & N/A \\
\hline Cupule outside & $\begin{array}{c}\text { Faintly or very faintly } \\
\text { visible hairs }\end{array}$ & $\begin{array}{l}\text { Densely fulvous-tomen- } \\
\text { tose }\end{array}$ & $\begin{array}{c}\text { Densely fulvous tomen- } \\
\text { tose by stellate hairs }\end{array}$ \\
\hline $\begin{array}{l}\text { Horizontal rings in } \\
\text { cupule }\end{array}$ & $\begin{array}{c}\text { 6-7, dimly concentric } \\
\text { flanges }\end{array}$ & $\begin{array}{c}5-8, \text { thin, more or less } \\
\text { concentric }\end{array}$ & $\begin{array}{c}5-7, \text { more or less con- } \\
\text { centric }\end{array}$ \\
\hline Nut enclosure & $\begin{array}{c}\text { Enclosing ca. } 1 / 2-2 / 3 \text { of } \\
\text { the nut }\end{array}$ & $\begin{array}{c}\text { Almost completely cover- } \\
\text { ing the nut }\end{array}$ & $\begin{array}{c}\text { Completely enclosing } \\
\text { the nut }\end{array}$ \\
\hline Infructescence length & $15-25 \mathrm{~cm}$ long & $10-25 \mathrm{~cm}$ long & $8-20 \mathrm{~cm}$ long \\
\hline
\end{tabular}

staff member of Dong Nai Culture and Nature Reserve has collected this species at Ma Da, Vinh Cuu, Dong Nai Province, indicating its wide distribution around the type locality. However, at present we have no reliable information on its population size. Further investigations are needed to determine the conservation status and actual population size in its natural habitat.

\section{Acknowledgements}

The authors wish to thank the colleagues in Department of Biology, Dalat University for their help collecting samples in the field. Our gratitude goes to the curators and staff of the following herbaria, ANDA, BKF, DLU, FU, HN, K, KYO, L, P and VNM for making their materials accessible. This study was supported by the Environment Research and Technology Development Fund (S9) of the Ministry of the Environment, Japan. 


\section{References}

Ban NT (2000) Flora of Vietnam, Vol. 1. Science and Technics Publishers, Hanoi.

Ban NT, Ly DT, Tap N, Dung VV, Thin NN, Tien VN, Khoi KN (2007) Vietnam Red Book Part II. Plants. Natural Sciences and Technology Publishers, Hanoi. [In Vietnamese]

Cannon CH (2001) Morphological and molecular diversity in Lithocarpus (Fagaceae) of Mount Kinabalu. Saban Parks Nature Journal 4: 45-69.

Deng M, Zhou ZK, Coombes A (2010) Lectotypification and new synonymy in Quercus subg. Cyclobalanopsis (Fagaceae). Novon: A Journal for Botanical Nomenclature 20(4): 400-405. doi: $10.3417 / 2004208$

Dung LV (2005) Fagaceae in Bidoup National Park. Published by the author. [In Vietnamese] Ho PH (2003) An Illustrated Flora of Vietnam Vol. 2. Young Publishing House, Ho Chi Minh City, 951 pp. [In Vietnamese]

Huang CJ, Zhang YT, Bartholomew B (1999) Fagaceae. In: Zhengyi W, Raven PH, Deyuan H (Eds) Flora of China. Volume 4, 333-369. http://www.efloras.org

IUCN (2012) IUCN Red List Categories and Criteria: Version 3.1. Second edition. IUCN, Gland, Switzerland and Cambridge, $32 \mathrm{pp}$.

Lam Dong Province Peoples' Committee (2008) Biodiversity conservation action plan 2008 2020. [In Vietnamese; published by the author]

Linh DT, Thanh NT, Cuong NT, Hai DV, Hoan DT (2013) Basis of taxonomy for Lithocarpus Blume (Fagaceae Dumort.) in Vietnam. In: Proceeding of The 5-th National conference on Ecology and Biological resources. Institute of Ecology and Biological resources, Hanoi, $127-131$.

Manos PS, Cannon CH, Oh S-H (2008) Phylogenetic relationships and taxonomic status of the paleoendemic Fagaceae of Western North America: Recognition of a new genus, Notholithocarpus. Madroño 55: 181-190. doi: 10.3120/0024-9637-55.3.181

Phengklai C (2008) Fagaceae. In: Santisuk T, Larsen K (Eds) Flora of Thailand 9(3). The Forest Herbarium, Bangkok.

Soepadmo E (1972) Fagaceae. Flora Malesiana Series I, Volume 7(2). Noordhoff-Kolff N.V., Djakarta, 339.

Strijk J, Sirimongkol S, Rueangruea S, Ritphet N, Chamchumroon V (2014) Lithocarpus orbicarpus (Fagaceae), a new species of Stone Oak from Phang Nga province, Thailand. PhytoKeys 34: 33-46. doi: 10.3897/phytokeys.34.6429

The Plant List (2013) Version 1.1. Published on the Internet. http://www.theplantlist.org/ [accessed 10th March, 2016]

UNESCO (2015) Twenty new sites added to UNESCO's World Network of Biosphere Reserves. http://www.unesco.org/new/en/member-states/single-view/news/twenty_new_ sites_added_to_unescos_world_network_of_biosphere_reserves/\#.Vu-QIMcpp8f [accessed 10th March, 2016]

Vuong DH, Xia NH (2014) Two new species in Castanopsis (Fagaceae) from Vietnam and their leaf cuticular features. Phytotaxa 186(1): 29-41. doi: 10.11646/phytotaxa.186.1.2 